\title{
Analysis on fluorescence, functional groups and optical behaviour of DL- Valine Cadmium Acetate and DL-Valine Zinc Acetate crystals
}

\author{
K.Suganya $^{1}$, V.S.Kumar ${ }^{2 *}$, B. Samuel Ebinezer ${ }^{1}$, R.S. Sundararajan ${ }^{1}$ \\ ${ }^{1}$ Department of Physics, Government Arts College(Autonomous), Kumbakonam, Tamilnadu, India \\ ${ }^{2}$ Department of Physics, Swami Dayananda College of Arts and Science, Manjakkudi, India \\ "Corresponding author e-mail: shanmugavsk.2010@gmail.com
}

Available online at: www.isroset.org

Received:18/Sept/2018, Accepted:11/Oct/2018, Online: 31/Oct/2018

\begin{abstract}
Single crystals of DL-Valine Cadmium Acetate and DL-Valine Zinc Acetate crystals have been grown by slow evaporation technique. Good quality crystals were grown in 20 days. The fluorescence of the crystals were analyzed by fluorescence studies. FTIR spectrum reveals the functional groups of the crystals. The crystals have good optical nature in the entire UV-Visible region. Structural morphology of the crystals were visualized by SEM technique.
\end{abstract}

Keywords- DLVCA - DL-valine cadmium acetate ; DLVZA - DL-valine zinc acetate; FTIR - Fourier transform infrared spectrum; UV-VIS region - ultra violet-visible region, SEM-Scanning Electron Microscope.

\section{INTRODUCTION}

A material which prologuly satisfies optical transparency and structural morphology is suitable for the optoelectronics device fabrication. It is very difficult to identify such a material with all requirements. Number of amino acid complexes with inorganic compound play a vital role in this aspect. Amino acid having the absence of strong conjugated bonds leads to wide transparency in the entire UV-Visible region[1].

In this paper, the growth and characterization of semiorganic crystals DL-valine with Zinc acetate and DLvaline with cadmium acetate are discussed. The grown crystals are effective in giving good optical, fluorescence behavior with expected vibrational modes which can be utilized for opto-electronic device fabrications.

\section{EXPERIMENTAL PROCEDURE}

A. Synthesis

High purity salts $(99.9 \%)$ were used for the crystal growth. Single crystals of DL-valine cadmium acetate(DLVCA) and DL-valine zinc acetate(DLVZA) were grown at room temperature by solution growth using slow evaporation method in equal stoichiometric ratio of each. The temperature of water in the bath was controlled digitally by using microprocessor. Variation in temperature of the bath can be tuned to an accuracy of $\pm 0.1^{\circ} \mathrm{C}$. Transparent good quality of both the crystals were harvested in span of 90 days. The photograph of the DLVCA and DLVZA crystals are shown in fig.1.

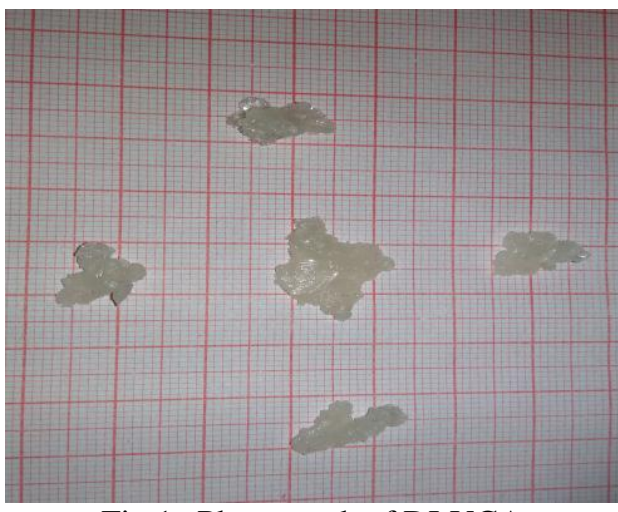

Fig.1a Photograph of DLVCA

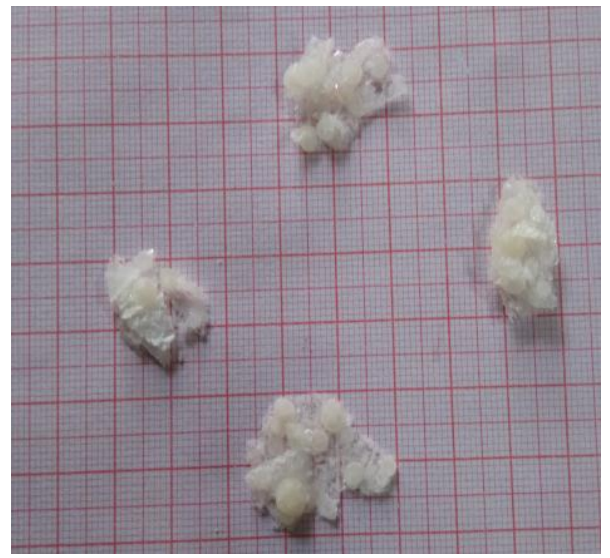

Fig.1b Photograph of DLVZA 


\section{CHARACTERIZATION}

The fluorescence studies of the grown DLVCA and DLVZA crystals were carried out using LS45 spectrofluormeter.. FTIR spectrum analysis was recorded in the range of 4000-400 $\mathrm{cm}^{-1}$ using Perkin Elmer spectrum RX I. The UV-Visible spectrum was recorded in the range 200nm-1100nm using Perkin Elmer lambda 35 model. Surface morphology of the crystals were displayed using SEM analysis.

\section{RESULTS AND DISCUSSION}

\section{A. Fluorescence studies}

Property of fluorescence is used to determine the crystalline quality as well as its exciton and in biochemical, medical, and chemical research fields for analyzing organic compounds. The fluorescence spectra of both crystals are observed given in figure. The fluorescence emission spectra for DLVCA and DLVZA crystal samples were recorded in the range from $240-$ $700 \mathrm{~nm}$. The excitation wavelength for grownup DLVCA crystal was found to be $247.35 \mathrm{~nm}$ and $353.09 \mathrm{~nm}$ for DLVZA crystal. The broadband is centered at $453.86 \mathrm{~nm}$ for DLVCA and $454.30 \mathrm{~nm}$ for DLVZA.

A peak at 531.66 was observed in the emission spectrum for DLVCA and 477.70 for DLVZA. The result indicates that the DLVCA crystals have a green fluorescence and blue fluorescence for DLVZA. These results indicate that these crystals may be used as colour light emitting materials.

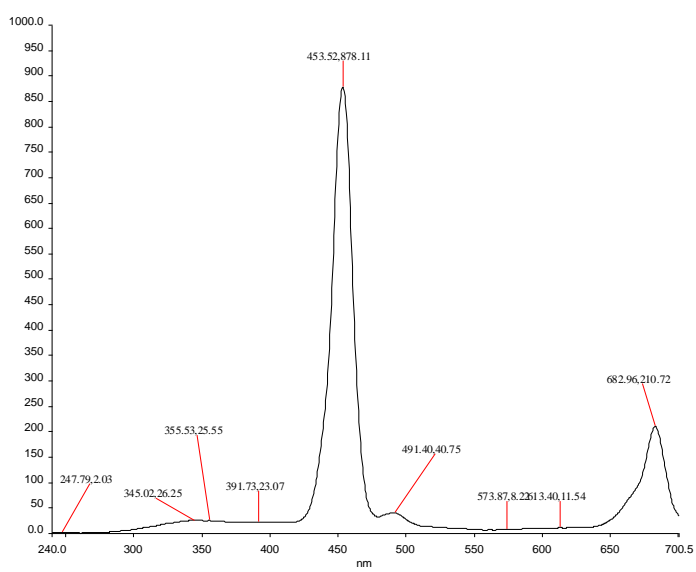

Fig.2(a) Fluorescence peak of DLVZA

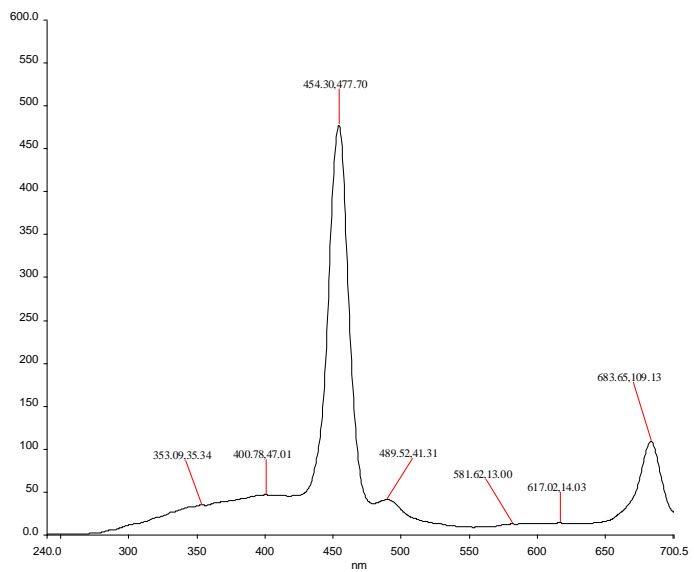

Fig.2(a) Fluorescence peak of DLVCA

B. Fourier Transform Infrared spectrum studies

The FTIR spectrum was recorded for the sample of the crystals using the $\mathrm{KBr}$ pellet technique in the region 4000$400 \mathrm{~cm}^{-1}$. The various functional groups present in the material are identified in this study[2-5]. The FTIR spectrum is shown in fig. 3 .

Table: FTIR spectral comparison between DLVCA and DLVZA

\begin{tabular}{|c|c|c|}
\hline DLVCA & DLVZA & Assignment mode \\
\hline 3441 & - & $\mathrm{NH}_{2}$ streching \\
\hline 3357 & - & $\mathrm{O}-\mathrm{H}$ stretching \\
\hline 3293 & - & $\mathrm{O}-\mathrm{H}$ stretching \\
\hline 2965 & 2962 & $\begin{array}{l}\text { O-H carboxylic acid- } \\
\text { strechting }\end{array}$ \\
\hline 2938 & - & $\begin{array}{l}\text { O-H carboxylic acid- } \\
\text { strechting }\end{array}$ \\
\hline 2879 & 2880 & $\begin{array}{l}\text { O-H carboxylic acid- } \\
\text { strechting }\end{array}$ \\
\hline 2746 & - & $\begin{array}{l}\text { O-H carboxylic acid- } \\
\text { strechting }\end{array}$ \\
\hline 1558 & 1565 & N-H deformation \\
\hline 1420 & 1406 & C-N stretching \\
\hline 1358 & 1361 & $\begin{array}{l}\text { stretching } \\
\text { symmetric }\end{array}$ \\
\hline 1328 & - & $\mathrm{II}_{\text {stretching }}$ \\
\hline 1286 & - & C-O stretching \\
\hline 1145 & 1141 & C-O-C stretching \\
\hline
\end{tabular}




\begin{tabular}{|l|l|l|}
\hline 1080 & 1080 & C-O stretching \\
\hline 1131 & 1122 & C-O stretching \\
\hline 1030 & - & C-N stretching \\
\hline 820 & 832 & $\begin{array}{l}\text { CH out of } \\
\text { deformation plane }\end{array}$ \\
\hline 770 & - & $\begin{array}{l}\text { CH out of } \\
\text { deformation plane }\end{array}$ \\
\hline 748 & - & $\begin{array}{l}\text { CH out of } \\
\text { deformation plane }\end{array}$ \\
\hline 563 & 578 & $\begin{array}{l}\text { II } \\
\text { CO rocking }\end{array}$ \\
\hline
\end{tabular}

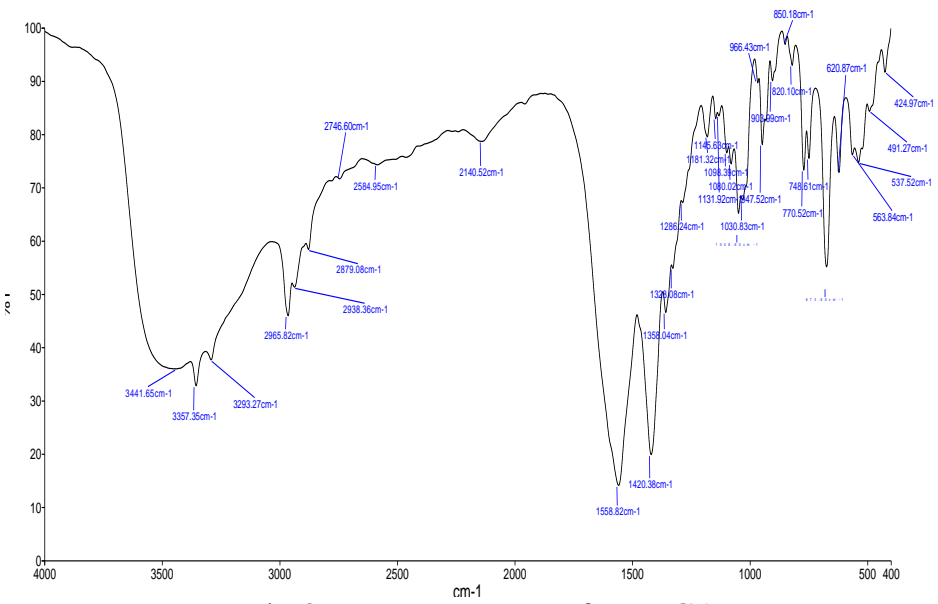

Fig.3a FTIR spectrum of DLVCA

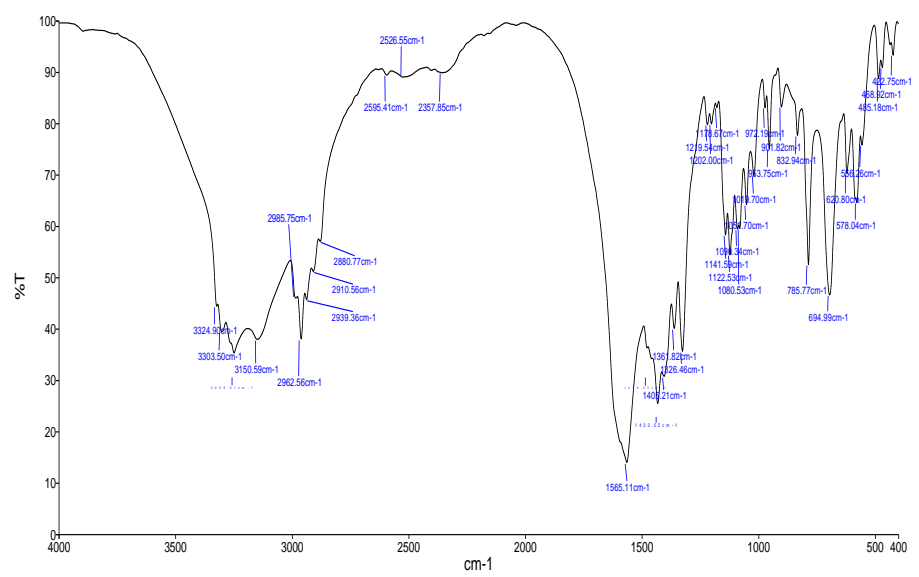

Fig.3b FTIR spectrum of DLVZA

C. UV-Visible spectral studies

The optical absorption spectra of DLVCA and DLVZA crystals were recorded in the region 200-1100nm at a scanning speed of $480 \mathrm{~nm} / \mathrm{min}$. Fig. 4(a\&b) shows the absorbance spectra and transmission spectra which hold good in the entire visible region. The cutoff wavelength of DLVCA was found to be $212 \mathrm{~nm}$ and $225 \mathrm{~nm}$ for DLVZA. The optical behavior of this DLVCA crystal was suitable for opto-electronic applications when compared to DLVZA crystal.

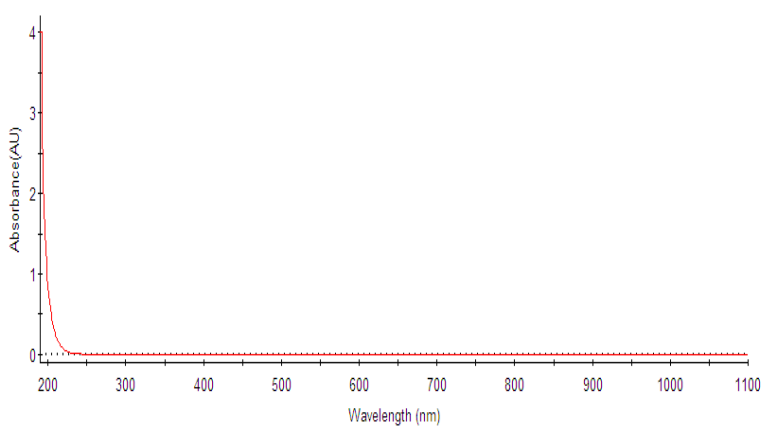

Fig.4(a) Absorption spectrum of DLVZA

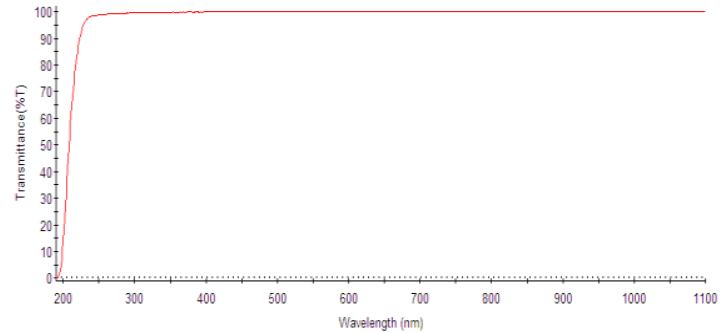

Fig.4(b) Transmission spectrum of DLVZA

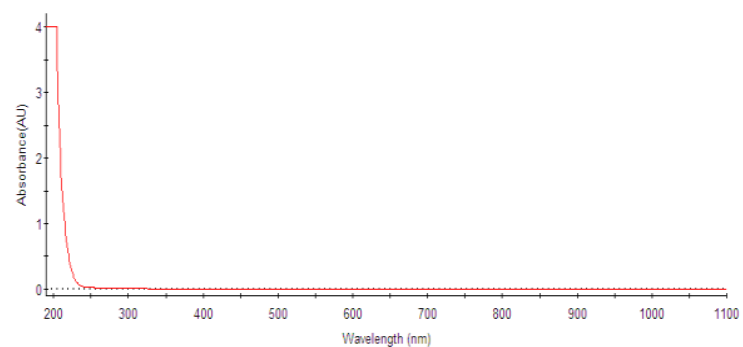

Fig.4(c) Absorption spectrum of DLVCA

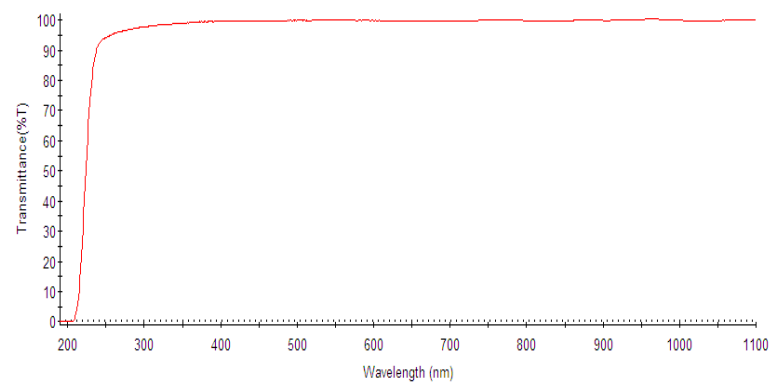

Fig.4(d) Transmission spectrum of DLVCA

D. SEM analysis

SEM analysis shows that the DLVCA image[fig.5(a) ] displays like a diagenetically altered discoaster, whereas crystal DLVZA reveals the larger striations. 


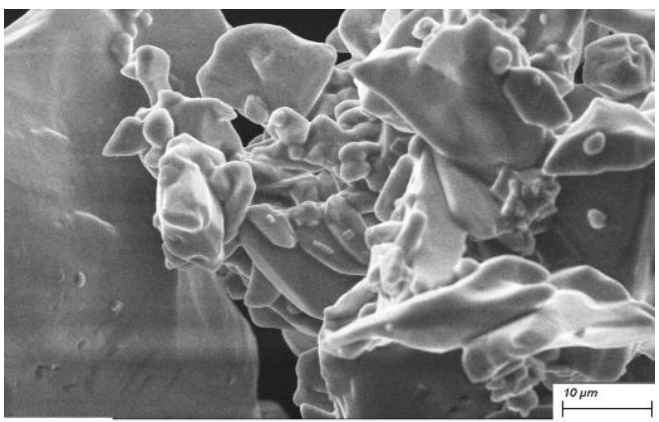

Fig.5(a) SEM image of DLVCA

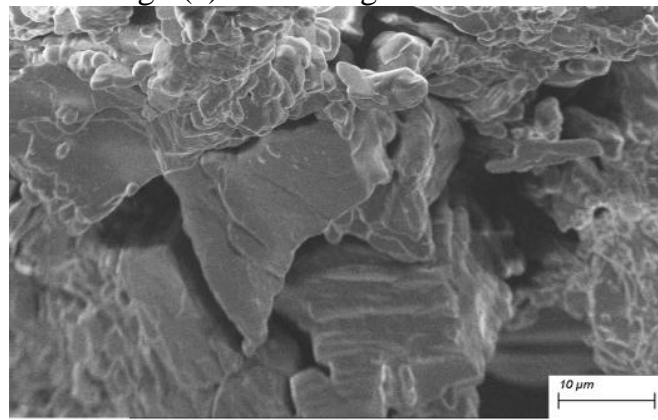

Fig.5(b) SEM image of DLVZA

\section{CONCLUSION}

Single crystals of DL-valine cadmium acetate and DL-valine zinc acetate have been grown by slow evaporation technique. The fluorescence spectra of both crystals are observed. The DLVCDA crystal is in the range of green light and DLVZA crystal is in the range of blue light emitting materials. FTIR spectrum reveals the functional groups of the grown compound crystals are upto hope. The crystal has good optical character in the entire UV-Visible region. The structural morphology of these crystals are also displayed. Further this new crystal material may be considered for opto electronic applications.

\section{ACKNOWLEDGEMENTS}

The authors are thankful to ACIC, St. Joseph's College for the spectral studies.

\section{REFERENCES}

[1] Tanusree K., Amino acids-precursors for synthesizing non linear optical.Mater.Prog.Cryst. Growth Ch.Mat., 2012, 58,74-83.

[2] George Socrates, Infrared and Raman Characteristics group frequencies Tables and Charts, $3{ }^{\text {rd }}$ Edition.

[3] Foil A. Miller and Charles H. Wilkins, Infrared Spectra and characteristic frequencies of inorganics ions, vol.24.no.8Aug.1952[1253-1294].

[4] John Coates, Interpretation of Infrared spectra, A practical approach, Encyclopedia of analytical chemistry, John Wiley and son Ltd., Chichester(2000)[1-23].

[5] Jospeh B. Lambert,et.al, Introduction to organic spectroscopy, MacMillan Pub.NY(1987). 